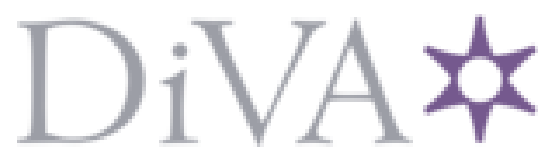

http://www.diva-portal.org

This is the published version of a paper published in Scandinavian Journal of Caring Sciences.

Citation for the original published paper (version of record):

Johansson, A., Andershed, B., Anderzen-Carlsson, A. [Year unknown!]

Conceptions of mental health care: From the perspective of parents' of adult children suffering from mental illness.

Scandinavian Journal of Caring Sciences

Access to the published version may require subscription.

N.B. When citing this work, cite the original published paper.

Permanent link to this version:

http://urn.kb.se/resolve?urn=urn:nbn:se:oru:diva-34617 


\title{
Conceptions of mental health care - from the perspective of parents' of adult children suffering from mental illness
}

\author{
Anita Johansson RN (Doctoral Student) ${ }^{1,2}$, Birgitta Andershed RNT, PhD (Professor) ${ }^{3,4}$ and Agneta \\ Anderzen-Carlsson RNT, PhD (Research Supervisor) ${ }^{5}$ \\ ${ }^{1}$ School of Health and Medical Sciences, University of Örebro, Örebro, Sweden, ${ }^{2}$ Division of Psychiatry, Skaraborg Hospital, Skövde, \\ Sweden, ${ }^{3}$ Department of Palliative Research Centre, Ersta Sköndal University College and Ersta Hospital, Stockholm, Sweden, ${ }^{4}$ Department \\ of Nursing, Gjøvik University College, Norway and ${ }^{5}$ Centre for Health Care Sciences, Örebro County Council, Örebro, Sweden
}

Scand J Caring Sci; 2013

\section{Conceptions of mental health care - from the perspective of parents' of adult children suffering from mental illness}

The aim of this study was to describe parents' conceptions of the mental health care provided to adult children suffering from mental illness. Data were collected using qualitative research interviews with a purposive sample of sixteen mothers and ten fathers. Phenomenographic analysis was used to identify conceptions and formulate descriptive categories. The first category, questioning the availability of care, describes mental health care as being unequal in terms of accessibility and lacking in continuity. The second category, disapproval of parental exclusion, illustrates conceptions that mental healthcare professionals disregard parents and do not provide them with adequate information. The third category, questioning the quality of care, encompasses conceptions of lack of trust in the professionals' competence, an unsatisfactory environment as well as inadequate cooperation with other healthcare providers and authorities. Positive aspects, such as being seen and confirmed, were mentioned as valuable by the parents.

Keywords: mother, father, parent, adult child, mental illness, mental health care, phenomenography.

Submitted 1 February 2013, Accepted 27 July 2013

\section{Introduction}

The 1990s was a period of significant change in mental health care both nationally and internationally. In Sweden, the political strategy was to structure mental health care in order to enable mentally ill patients to live as normal a life as possible (1). This meant transferring people suffering from mental illness from institutions to the local community. Two decades later, a gap remains between mentally ill persons' needs and the mental health care available $(2,3)$. Family members often fill these gaps. A recently published Swedish study revealed that family members spent an average of 22.5 hours/ week on care-related activities (4).

Family burden has been studied and compared from diverse perspectives within the Swedish psychiatric context. Families of mentally ill patients face many challenges and stressors, as well as reporting insufficient involvement in the patient's professional care (5). Regardless of whether the patient is admitted for the first

\section{Correspondence to:}

Anita Johansson, School of Health and Medical Sciences, Örebro University, 70182 Örebro, Sweden. E-mail: anita.ulla.

johansson@vgregion.se time or readmitted (6) voluntarily or compulsorily, the mental illness, social stigma and limitations in mental health care make the situation burdensome $(6,7)$. Family members have reported a negative attitude on the part of the mental health professionals, which in turn leads to feelings of powerlessness and alienation (8), being ignored and not considered a resource (9). Although the need to support family members has been highlighted, many professionals continue to focus only on the patient, while disregarding the relatives' issues (10).

These results correspond with those of several international studies, in which family members reported receiving inadequate support from mental healthcare professionals (11) and instead had to turn to relatives, friends and support groups (12). Feelings of being alienated, taken for granted and carrying an unbearable burden were described (13-15). Family members' wish to obtain information and be involved in the care has been viewed as secondary $(16,17)$ by healthcare professionals, who are said to be suspicious of parental involvement and often refuse to allow parents to participate (18). Moreover, they argue that they are obliged to maintain patient confidentiality $(10,13)$. In the study by MurraySwank et al. (19), 67\% of persons suffering from serious mental illness stated that they wanted family members to 
participate in their care. In another study, patients who failed to obtain support from family members were reported to be more dissatisfied with their care than those who received family support (20). It has also been reported that lack of knowledge and information constitutes an obstacle to family involvement (21). In order to overcome some of these barriers, Cleary et al. (22) highlighted the importance of providing family members with support, information and education. In Sweden, legislation has been introduced to strengthen family members' opportunities to participate in formal health care (23) by stipulating that in cases where information cannot be provided to the patient, it should be provided to the family members, unless there are specific reasons that make such provision inappropriate (24).

Despite the fact that family members' experiences in this area have been relatively well documented, there is still a knowledge gap in terms of the parental perspective. Healthy young people's dependence on their parents has increased in terms of economic, practical and social support. Many remain in the family home due to increased educational requirements, uncertainty on the labour market as well as changed values and norms (25), which may be even more true of young adults who suffer from mental illness. Such illness is long term, often chronic and leads to social difficulties, which means that the parents are the ones who provide the most support.

\section{Aim}

The aim of the present study was to describe parents' conceptions of the mental health care provided to adult children suffering from mental illness.

\section{Design and methodology}

A descriptive qualitative design with a phenomenographic approach was employed in order to describe variations in the parents' conceptions of the mental health care. The method distinguishes between the first-order perspective, how something really is and the more essential second-order perspective, where the researcher is primarily concerned with how phenomena are perceived or appear to someone. Phenomenographic study design aims at focusing on the second-order perspective to study the variation in people's conceptions of a given phenomenon in the surrounding word. Although based on individual experiences, the result provides a description on a collective level $(26,27)$.

\section{Participants}

The study took place in western Sweden. The participants were recruited through an advertisement that appeared on two occasions in local newspapers. The inclusion criteria were parent of an adult child (over 18 years of age) with long-term (more than two years) mental illness (psychotic, mood or anxiety disorder without concurrent intellectual impairment or substance abuse) and regular contact between parent and child. Of totally 39 responded parents', sixteen mothers and ten fathers were assessed as eligible for the study and all agreed to participate. Six of these parents were couples. The sociodemographic characteristics of the participants and their adult children are presented in Table 1 and 2 respectively.

\section{Data collection}

The interviews were conducted by the first author from June 2007 to April 2008. The participants were encouraged to relate their experiences in narrative way. An open interview guide, in line with the phenomenographic tradition (27), covering two main areas, was used to ensure that the participants' narratives covered the areas of interest. The main question for this present study was 'Can you please tell me about your experiences of mental health care?' Probing questions were posed in order to obtain a deeper understanding of their conceptions. The

Table 1 Sociodemographic characteristics of the study population $(n=26)$

\begin{tabular}{|c|c|c|}
\hline Variable & Number & Years \\
\hline \multicolumn{3}{|l|}{ Sex } \\
\hline Female & 16 & \\
\hline Male & 10 & \\
\hline \multicolumn{3}{|l|}{ Age (years) } \\
\hline 40-49 & 4 & \\
\hline $50-59$ & 9 & \\
\hline $60-69$ & 9 & \\
\hline$>70$ & 4 & \\
\hline Average age & & 60 \\
\hline \multicolumn{3}{|l|}{ Education } \\
\hline Not stated & 1 & \\
\hline Primary/secondary school & 15 & \\
\hline College/university education & 10 & \\
\hline \multicolumn{3}{|l|}{ Employment } \\
\hline Employed & 16 & \\
\hline Retired & 10 & \\
\hline \multicolumn{3}{|l|}{ Civil status } \\
\hline Living with the child's mother/father & 11 & \\
\hline $\begin{array}{l}\text { Living with a partner, not the } \\
\text { child's mother/father }\end{array}$ & 7 & \\
\hline Widowed/Single & 8 & \\
\hline Living with son/daughter & 5 & \\
\hline \multicolumn{3}{|l|}{ Member of a support group } \\
\hline Yes & 4 & \\
\hline No & 22 & \\
\hline \multicolumn{3}{|c|}{ Informed the child of participation in the study } \\
\hline Yes & 12 & \\
\hline No & 14 & \\
\hline
\end{tabular}


Table 2 Sociodemographic characteristics of the mentally ill children $(n=23)$

\begin{tabular}{|c|c|c|}
\hline Variable & Number & Years \\
\hline \multicolumn{3}{|l|}{ Sex } \\
\hline Female & 16 & \\
\hline Male & 7 & \\
\hline \multicolumn{3}{|l|}{ Age (years) } \\
\hline $18-29$ & 12 & \\
\hline $30-39$ & 7 & \\
\hline $40-49$ & 4 & \\
\hline Average age & & 30 \\
\hline \multicolumn{3}{|l|}{ Diagnosis } \\
\hline Schizophrenia & 8 & \\
\hline Depression & 5 & \\
\hline Anxiety disorder & 1 & \\
\hline Unknown to the parents & 9 & \\
\hline \multicolumn{3}{|c|}{ Length of time since the onset of mental illness (years) } \\
\hline $3-9$ & 14 & \\
\hline $10-16$ & 6 & \\
\hline $17-24$ & 3 & \\
\hline Average length of time since onset & & 9 \\
\hline \multicolumn{3}{|l|}{ Civil status } \\
\hline Living with mother/father & 4 & \\
\hline Living in own household with a partner ${ }^{a}$ & 3 & \\
\hline Living in own household without a partner ${ }^{a}$ & 16 & \\
\hline
\end{tabular}

${ }^{\mathrm{a}}$ Four adult children were living with own children, of which two lived without a partner and two lived together with a partner.

interview guide also covered the parental experiences of everyday life, results which have been described elsewhere $(28,29)$. Two pilot interviews (one with a mother and one with a father) were conducted to test the relevance of the interview questions as well as their validity in relation to the aim of the study, both of which were included. The participants chose the location for the interviews; most were conducted at a psychiatric outpatient clinic (A.J. workplace), several in the participant's home and two at the participant's workplace. All interviews were audio-taped and lasted from 52 to $107 \mathrm{~min}$ ute (average 58 minute). Two to six weeks after the interviews the first author telephoned the participants to pose clarifying questions and give them an opportunity to add new information. These conversations were also audio-taped and included in the data set.

\section{Data analysis}

The audio-taped interviews were transcribed verbatim. In the data analysis, similarities and differences within the parents' statements were focused on, in accordance with phenomenographic methodology. The analysis was guided by the consecutive steps described by Sjöström and Dahlgren (30). In the first step, familiarisation, the transcripts were read several times to become familiar with the data. The second step, compilation, consisted of the identification of significant statements most in line with the aim of the study. We searched for parental conceptions of mental health care. In the next step, condensation, longer statements were condensed to reveal their essence. In the fourth step, grouping or classification, similar statements were brought together and preliminary conceptions formulated. Up to this stage, the QRS NVIVO 8 (QSR International Pty Ltd, Doncaster, Victoria, Australia) software was utilised as a tool in the data analysis. In the fifth step, comparison, the conceptions were compared to find dividing lines between them in order to ensure that they differed from each other. The conceptions were thereafter grouped into preliminary descriptive categories. The sixth step consisted of naming the descriptive categories to highlight their essence. The final step was a contrastive comparison of categories, which involved outlining the unique character of each category as well as description of the similarities between them (30). The authors continuously discussed the analysis process.

\section{Ethical considerations}

The participants received oral and written information explaining the aim of the research that participation was voluntary, that they could withdraw from the study at any time and that the data would be treated confidentially. They signed a written consent form before the interviews (31).

This study covers issues that could be experienced as private and emotional. Therefore, it was regarded as valuable that the interviewer, by her profession as a psychiatric nurse was skilled in talking to vulnerable persons about sensitive matters. A qualitative open-ended interview approach seemed appropriate, as the interviewer there could be attentive to the any signs of the participant not feeling at ease with the interview situation. Practice-oriented research requires sensitivity to what happens in the interview situation (32). After the interview session, time for reflection was provided. The follow-up telephone conversation gave the parents the possibility to talk about their experiences of the interview situation and an opportunity to add or exclude some details.

\section{Findings}

Three descriptive categories based on seven conceptions related to how parents perceived mental health care were identified (Table 3). Overall, the categories represent negative conceptions, although the parents also mentioned some positive aspects. Both mothers' and fathers' statements are represented in all the conceptions. Mothers and fathers will be referred to as parents below, unless otherwise indicated. 
Table 3 Each descriptive category illustrates different conceptions of the mental health services as experienced by the parents

\begin{tabular}{|c|c|c|c|}
\hline Descriptive categories & Questioning the availability of the care & Disapproval of parental exclusion & Questioning the quality of care \\
\hline \multirow[t]{2}{*}{ Conceptions } & Unequal access & Ignoring the parents & Mistrusting competence \\
\hline & Lack of continuity & Lack of information & $\begin{array}{l}\text { More storage than care } \\
\text { Inadequate cooperation with other } \\
\text { health care providers and authorities }\end{array}$ \\
\hline
\end{tabular}

\section{Questioning the availability of care}

This descriptive category comprises the two conceptions: unequal access and lack of continuity.

Unequal access. The parents perceived that it was difficult to access adequate mental health care for their adult children and expressed that they had to be strong in order to fight for their child's needs. Parents with experience of both mental and physical illness found that people with mental illness had less access to all forms of health care.

Parents with experience of both child and adult psychiatry were of the opinion that access to care differed between these two settings. In child psychiatry, there was a family-oriented perspective with frequent followups, while adult psychiatry focused on the individual patient to a greater extent with fewer follow-ups. The latter left the parents with a heavy burden of responsibility. Some mothers who had insight into the health care offered thanks to their profession and believed that such knowledge was beneficial:

I'm convinced that we have been treated differently because I'm a nurse and know the system. They listened. I succeeded in gathering the right professionals around my child. Otherwise I would have had to accept something inferior in the way of doctors, treatment interventions etc.

Some parents were convinced that the choice of treatment interventions was to a greater extent dictated by where the child lived and the psychiatric unit's resources than her/his needs. For example, their children had been allocated counselling with a nurse when there was a shortage of psychologists.

Lack of continuity. All parents described a lack of continuity in their child's mental health care. They wished for stable contact with a single psychiatrist, but had experienced poor continuity due to locum psychiatrists. The parents stated that meeting a different psychiatrist each time hindered the creation of a trusting relationship between the professionals and the adult child, leading to unnecessary suffering for the latter. Long gaps between the child's appointments had resulted in relapse and even compulsory institutional care. From a parental perspective, lack of continuity caused delays and a lack of stability in the child's care. Continuity was also of great importance for the parents:

It was the physiotherapist... who realised that my daughter needed to talk [to a nurse] on a regular basis... It was such a relief! It has relieved the pressure on me... In fact, it's the main reason things have stabilised... Now I know that she has an appointment with the nurse... when she [daughter] talks about something it's so easy for me to say... 'but talk to the nurse about it when you see her'.

Only one parent reported a well-organised and wellfunctioning cooperation with good continuity throughout the child's entire illness. This positive experience included contact with child psychiatry, cooperation between outpatient and inpatient care and a wellplanned transfer to adult psychiatry.

\section{Disapproval of parental exclusion}

This descriptive category is based on two conceptions: ignoring the parents and lack of information.

Ignoring the parents. The parents perceived being ignored by the professionals. They regarded themselves as important resources in their child's life and emphasised the value of cooperation between parents and professionals in order to highlight the child's situation from different perspectives. When not included, the parents felt worthless, ignored and expressed frustration about being unable to influence the mental health care. On the other hand, many parents felt that they were taken for granted and left with the responsibility to support the child. One mother expressed this as being 'Her child's therapist' and questions such as 'How would health care manage without parents?' and 'How do the children who have no parents manage?' were frequently raised. In their attempts to ensure that the child's needs were met, several parents felt questioned and misjudged by the professionals. When trying to cooperate, the parents often had the impression that their suggestions were not welcome. One mother described this as follows:

It would be great if my daughter could be allocated more time so that she could get out for walks... I wish I could put forward a wish in that way without being misunderstood or it being considered interference or that my demands are excessive. 
Despite the emphasis on cooperation between professionals, children and parents, the professionals often referred to confidentiality as the reason for excluding parents from the care.

The parents frequently reported that their burdensome situation had been ignored. They wished that the professionals would ask them what it is like to be a parent of an adult child with mental illness. However, they also mentioned some positive conceptions of being valued and supported:

When we were seen... and were not only criticised... then we suddenly became human beings, we became relatives, felt that we were accepted and we could phone and received support in our sorrow and all that. It felt really good but getting there has taken a long time, to feel that you can trust them.

Parents who had participated in support groups for next-of-kin $(\mathrm{n}=4 / 26)$ stated that such activities were very helpful.

Lack of information. The majority of parents stated that professionals did not provide them with adequate information about the child's mental illness and care plan. They lacked clear guidelines and tools to support their children in the best possible way:

We learnt after several years that a treatment programme existed for our child, why weren't we told about it at once?

The parents were of the opinion that knowledge of the disease would facilitate them to help the child to better comply with the care provided. Many parents had to request information and felt obliged to seek knowledge themselves. Searching for knowledge was difficult when they were not aware of the child's diagnosis. Parents who had experienced compulsory institutional care stated that they had obtained clearer information on such occasions compared to when the child was cared for on a voluntary basis.

They suggested that at the onset of the illness and in emergency situations, information from the professionals should be adapted and repeated to a greater extent in accordance with parental needs.

The mental healthcare environment was often viewed as strange and frightening. The fact that even voluntary inpatient care took place behind locked doors was described as difficult to understand.

\section{Questioning the quality of care}

This descriptive category includes three conceptions: mistrusting competence, more storage than care and inadequate cooperation with other healthcare providers and authorities.

Mistrusting competence. The parents were of the opinion that the professionals did not always have the necessary competence and that they often acted in an unprofessional manner. They described being blamed for causing the child's mental illness and hindering her/his recovery. Some had also experienced that the professionals spoke about them in a negative way to the child. At times the professionals exhibited an authoritarian attitude and lack of respect. The parents wanted to be seen, respected and have their own and the child's opinions taken into account to a higher degree:

It's basically that you are stupid. My daughter says...'it's no use saying anything because they [mental health professionals] don't believe me' ... it leaves you with no foot to stand on, it's like banging your head against a wall, you don't get anywhere. They don't trust or believe her or me, especially not my daughter.

Sometimes parents considered care provided by nurses insufficient and a temporary solution due to lack of available resources. Likewise, they also experienced a lack of compassion on the part of professionals. This was exemplified as professionals being absent at planned visits, not informing when such visits were cancelled or forgetting agreements made at a previous session. Furthermore, the parents described the professionals as not being vigilant enough in view of the child's current mental health status, which laid a heavy responsibility on their shoulders:

When we phone them, we try to get staff members to request her to come in [when there is deterioration]... They don't phone or visit but send a letter... As she knows by now the way they work... she mails them a day or so beforehand saying I'm sorry but I can't come... that's the usual course of events... in the meantime, it [the condition] usually develops until it becomes so serious that she has to be compulsorily admitted.

Several expressed that the mental health care was slipping out of their control and described it as 'insufficient'. They had lost confidence in it, which meant that they had to support the child in ways they believed were the responsibility of the professionals.

More storage than care. The majority of parents were of the opinion that the long-term mental health care provided was unsuccessful. They reported that their child was unemployed, under-stimulated, isolated and had no opportunity to obtain meaningful employment. The parents emphasised that mental healthcare professionals should be more active in addressing young people's problems. Instead of effective care, some described the child as being numbed by medication, while others believed that it was administered on an experimental basis. Temporary solutions were described as 'more storage than care'. Voluntary care that included mandatory activities was described as confusing and contradictory.

My child has a major problem with balls... when you throw a ball towards her she becomes terror- 
stricken... The staff forced her... when she refused she wasn't allowed to go home by car but had to walk... Being unable to catch a ball is hardly a matter of life and death, as there are many other things you can do in life besides playing with a ball.

Lack of compassion on the part of health professionals meant that parents had to assume their duties. Some compared the mental healthcare service to an industry; individuals were machine parts, and there was no holistic or humanistic perspective.

Inadequate cooperation with other healthcare providers and authorities. The parents described a lack of cooperation between mental healthcare professionals and other authorities. The follow-up of care plans agreed at meetings with professionals and other authorities was not always fruitful. At times, poor cooperation with the employment authorities resulted in failure to take a holistic view of the child. Instead of recognising the child's skills and needs, she/he was regarded as workshy. On the other hand, cooperation could lead to adapted employment that increased the child's well-being, while reducing the parental burden.

He [son] works from 9 h00 to 12 h30 every day... in order to have a more structured day... I think it's really great that he is working now. He has his own place... but we are in regular contact with him... he has made friends and that relieves our burden... otherwise he would only have us.

Several parents experienced a great difference between child and adult psychiatry and believed that when planning the transfer between these settings, better cooperation was necessary.

\section{Discussion}

The present study aimed to describe parents' conceptions of the mental health care of adult children suffering from mental illness. The findings illustrate that the parents felt excluded and generally experienced the care as unsatisfactory; they questioned its availability and quality. These shortcomings were described as affecting the parents and their well-being.

Half of the mentally ill children in the present study were aged under 29 years. Their parents described the transfer from child to adult psychiatry as problematic. A heavy burden of responsibility was placed on the parents' shoulders as the adult psychiatry considered the child an autonomous person who had no need of social support from the parents, while the parents believed that the child needed both themselves and the professionals. Similar findings have been previously presented by Bruce and Evans (33). The perceived responsibility on the part of the parents illustrates that they believe that the parental role is important for the mentally ill child. From a theoretical perspective, parental care, 'mothering', has been described as independent of gender and as encompassing the moral responsibility of being able to determine when the child can stand on its own two feet. The latter is a delicate balance between letting go and holding on (34). When a healthy child moves towards adult life, dependence is gradually reduced and she/he forms close social ties herself/himself. However, being the parents of a mentally ill child who is trying to attain independence is more difficult as the child is dependent on them. This complex 'mothering' might also be the reason why the majority of parents had not told their child about the study, despite having a good relationship with her/him. They may have been afraid of jeopardising the relationship, as they were aware that the child needed them, yet wanted to participate and tell their story. The decision not to inform the child also corresponds with Lakeman's findings that in care characterised by family involvement, it is important to maintain confidentiality and respect for each other (21).

The parents also experienced a lack of understanding for their exhausted state as well as little cooperation between themselves and healthcare professionals. Despite feeling excluded and taken for granted, they perceived that the professionals expected them to contribute to the care. Mental healthcare professionals' attitudes have been reported to have an impact on family members' sense of alienation (8). The parents' sense of being marginalised can be discussed from a theoretical perspective based on the work of Andershed (35), who presented a theory of family involvement in care, involvement in the light and in the dark. The parents' feelings of uncertainty about the child's diagnosis and treatment hampered their understanding of her/his situation, thereby reducing their ability to help and alleviate her/his suffering. This can be referred to Andershed's (35) concept of involvement in the dark. Although the parents wanted to be involved in the professional care, the majority of parents were unaware of the content of their child's treatment plan. According to Swedish legislation (24), treatment plans should be formulated in order to meet individual needs. Professionals are responsible for assessing the need and, if appropriate, invite family members to participate in the planning. If family involvement is not the norm in the mental health care working culture, uncertainty about how to act, that is, respecting patient confidentiality in encounters with the family, could be used by professionals as an excuse to avoid contact with families (10). However, although the parents argued for participation in professional care, it is also important to consider the mentally ill person's need for independence and choice about the nature of family involvement. Not wanting to burden the family and scepticism about the value of family involvement are two barriers reported in relation to family participation (19). For the sake of patients, it is 
important for professionals and family members to find a balance in terms of sharing information so that the sick person can obtain the best possible care and support (36).

Access to mental health care was described as both difficult and unequal. The parents believed that the shortage of professionals with appropriate education as well as shortterm solutions had a negative impact on the child's recovery. It therefore seems important to inform and educate parents and other family members about the illness and treatment. Understanding treatment regimens and the role of the various professionals on the psychiatric team might help the parents to have more confidence in professional care and their own caring support. It could also improve the parents' well-being, as they might feel confirmed in their vulnerable situation. This is in line with findings from other studies on the importance of support and information (22), good relationships and clear communication between family members, professionals and patients (37, 38). Support for the child would be improved if formal care and informal care were to encounter each other with respect and view each other as complementary (36).

The parents' perceptions that mental health care was inflexible and lacked a holistic perspective reduced confidence in the care provided. Mandatory activities were described as a part of voluntary care. This in line with other studies that reported how the inequality between patients and professionals that is somehow an accepted part of mental health care leads to the risk of abuse of power. Professionals may invoke a coercion context even with voluntary patients (39) and strive to maintain a common approach in order to uphold power and decide about the patients' treatment (40). Although by its very nature compulsory care violates the individual's integrity, it has also been described as twofold in that it creates a sense of security for the patient who needs it (41). Professionals must become more aware of their own personal attitudes and attempt to take the same approach towards each individual patient (42).

In summary, despite the fact that mental healthcare research has been conducted for many years, there is still a knowledge gap in terms of cooperation between those involved in the mentally ill person's life. Why do parents of mentally ill adult children still feel excluded and marginalised? Patients with serious mental illness are dependent on their family members. The relationship between healthcare professionals and family members indirectly affects patient well-being. Scientific evidence has demonstrated that professionals are a vital link between family members and the mentally ill person (35). Strategies to improve many of the shortcomings identified in this study have been highlighted in the WHO's Global mental health action plan 2013-2020 (43), such as continuity of care between different providers and system levels as well as positive collaboration between formal and informal care givers.

\section{Methodological considerations}

Recruitment via advertisements and qualitative interviews in addition to the use of the phenomenographic method of analysis seemed appropriate for the present study. As a result of the recruitment strategy, we interviewed parents without the consent of their adult child. However, the parents' negative opinions of mental health care raise the question of whether the recruitment method influenced the result. Are dissatisfied parents more likely to answer an advertisement and participate in an interview than those who have more positive opinions? Compared to studies in which other recruitment strategies, for example via support groups $(14,18)$, were used, the results describe more negative experiences. However, the strengths are that our study population comprised parents from different sociodemographic groups, whose adult children had various forms of mental illness. Furthermore, the recruitment strategy might have had a positive impact on the number of fathers who volunteered to participate.

Use of QSR NVIVO 8 in the analyses is believed to have contributed to stability and consistency in the study as it facilitated compiling comparable lists of nodes and made it easy to move between the original data and the category system. In the methodological literature, it is recognised that computer programs are becoming indispensable tools for analysing qualitative data (44). Qualitative software does not analyse the data, but it does facilitate data storage, coding, retrieval, comparison and linking (45).

In order to further enhance credibility of the study, creative and reflective discussions were held between the authors throughout the analysis process, as well as at seminars with researchers from a psychiatric context. Within qualitative study design, such as phenomenography, there are no exact rules regarding the optimal sample size (46). The authors regarded that the twenty-six interviews were rich in information and that the later interviews tended to add no additional variation of the conception of the mental health care. It was therefore concluded that data saturation was achieved by the twenty-six interviews.

\section{Clinical implications}

It is essential to support parents who are informal caregivers by means of information and education about the nature of their child's illness and treatment regimens. The result indicates that it would be of value to implement and evaluate family collaboration interventions within the psychiatric context. In order to enhance the quality of the mental health care, we need more knowledge of its positive aspects and what patients and their family members regard as valuable. 


\section{Conclusion}

Parents and children are dependent on and influence each other. Many parents questioned their child's care and felt alone in supporting her/him. Cooperation between the child, parents and professionals provides opportunities to view the child's situation from different perspectives and could reduce worry and enhance the well-being of adult children who suffer from mental illness as well as that of their parents.

\section{Acknowledgements}

We thank the mothers and fathers for sharing their experiences.

\section{Author contributions}

All authors were responsible for the study design. Anita Johansson performed the data collection, analysis and drafted the manuscript. Birgitta Andershed and Agneta Anderzen-Carlsson critically revised the manuscript and supervised the study.

\section{Ethical approval}

The Regional Research Ethics Committee in Gothenburg approved the study (No. 112-07).

\section{Funding}

This study was supported by the Division of Psychiatry, Skaraborg Hospital, the Research Fund at Skaraborg Hospital, Skaraborg Research and Development Council and the Skaraborg Institute for Research and Development. The authors report no conflict of interest. The authors alone are responsible for the content and writing of this paper.

\section{References}

1 The National Board of Health and Welfare. Välfäd och valfrihet? Slutrapport från utvärderingen av 1995 års psykiatrireform (Swe) [Welfare and Freedom of Choice? Final Report from the Evaluation of the 1995 Mental Health Care Reform], 1999, The National Board of Health and Welfare, Stockholm.

2 The National Board of Health and Welfare. Stöd till personer som vardar eller stödjer närstående. Lägesbeskrivning 2010 (Swe) [Support for People who Care or Support Relatives], 2010, The National Board of Health and Welfare, Stockholm.

3 Stefansson CG, Hansson L. Mental health care reform in Sweden, 1995. Acta Psychiatr Scand Suppl 2001; 104: 82-88.

4 Flyckt L, Löthman A, Jörgensen L, Rylander A, Koernig T. Burden of informal care giving to patients with psychoses: a descriptive and methodological study. Int $J$ Soc Psychiatry 2013; 59: 137-46.

5 Östman M, Hansson L, Andersson K. Family burden, participation in care and mental health An 11-year comparison of the situation of relatives to compulsorily and voluntarily admitted patients. Int $J$ Soc Psychiatry 2000; 46: 191-200.

6 Östman M. Family burden and participation in care: differences between relatives of patients admitted to psychiatric care for the first time and relatives of re-admitted patients. J Psychiatr Ment Health Nurs 2004; 11: 608-13.

7 Östman M, Hansson L. The burden of relatives of psychiatric patients Comparisons between parents, spouses, and grown-up children of voluntarily and compulsorily admitted psychiatric patients. Nord J Psychiatry 2000; 54: 31-36.

8 Ewertzon M, Lutzen K, Svensson E, Andershed B. Family members' involvement in psychiatric care: experiences of the healthcare professionals' approach and feeling of alienation. J Psychiatr Ment Health Nurs 2010; 17: 422-32.

9 Sjöblom L-M, Wiberg L, Pejlert A, Asplund K. How family members of a person suffering from mental illness experience psychiatric care. Int J Psychiatr Nurs Res 2008; 13: 1-13.

10 Blomqvist M, Ziegert K. "Family in the waiting room:" a Swedish study of nurses' conceptions of family participation in acute psychiatric inpatient settings. Int $J$ Ment Health Nurs 2011; 20: 185-94.

11 Saunders JC. Families living with severe mental illness: a literature review. Issues Ment Health Nurs 2003; 24: 175-98.

12 Clarke D, Winsor J. Perceptions and needs of parents during a young adult's first psychiatric hospitalization: "we're all on this little island and we're going to drown real soon". Issues Ment Health Nurs 2010; 31: 242-7.

13 Nicholls E, Pernice R. Perceptions of the relationship between mental health professionals and family caregivers: has there been any change? Issues Ment Health Nurs 2009; 30: 474-81.

14 Weimand BM, Hedelin B, Hall-Lord ML, Sallstrom C. "Left alone with straining but inescapable responsibilities:" relatives' experiences with mental health services. Issues Ment Health Nurs 2011; 32: 703-10.

15 Wilkinson C, McAndrew S. "I'm not an outsider, I'm his mother!" A phenomenological enquiry into carer experiences of exclusion from acute psychiatric settings. Inter $J$ Ment Health Nurs 2008; 17: 392-401.

16 Goodwin V, Happell B. Conflicting agendas between consumers and carers: the perspectives of carers and nurses. Inter J Ment Health Nurs 2006; 15: 135-43.

17 Weimand BM. Experiences and nursing support of relatives of persons with severe mental illness, in Faculty of Social and Life Sciences, Department of Nursing 2012, Karlstad university, Karlstad, Sweden.

18 Jakobsen ES, Severinsson E. Parents' experiences of collaboration with 
community healthcare professionals. J Psychiatr Ment Health Nurs 2006; 13: 498-505.

19 Murray-Swank A, Glynn S, Cohen AN, Sherman M, Medoff DP, Fang LJ, Drapalski A, Dixon LB. Family contact, experience of family relationships, and views about family involvement in treatment among VA consumers with serious mental illness. J Rehabil Res Dev 2007; 44: 801-11.

20 Prince JD. Family involvement and satisfaction with community mental health care of individuals with schizophrenia. Community Ment Health J 2005; 41: 419-30.

21 Lakeman R. Family and carer participation in mental health care: perspectives of consumers and carers in hospital and home care settings. J Psychiatr Ment Health Nurs 2008; 15: 203-11.

22 Cleary M, Freeman A, Walter G. Carer participation in mental health service delivery. Int $J$ Ment Health Nurs 2006; 15: 189-94.

23 The National Board of Health and Welfare. Patientsäkerhetslagen (Swe) [Patient Safety Act], 2010, The Nationell Board of Health and Welfare, Stockholm.

24 The National Board for Health and Welfare. $3 f \&$ Hälso och sjukvårdslagen (Swe) [Health and Medical Services Act], 1982; Available from: http:// www.riksdagen.se/sv/Dokument-Lagar/Lagar/Svenskforfattningssamling/ Halso-och-sjukvards-

lag-1982_sfs-1982-763/?

bet $=1982: 763$.

25 Höjer I, Sjöholm Y. Att stå på egna ben - om övergången från samhällsvård till vuxenliv (Swe) [Standing on your own two feet on the transition from public care to adulthood]. Socialvetenskaplig tidskrift 2011; 1: 24-40.

26 Marton F. Phenomenography Describing conceptions of the world around us. Instr Sci 1981; 10: 177200.

27 Marton F, Booth S. Learning and Awareness. 1997, Lawrence Erlbaum Associates Mahawa, New Jersey.
28 Johansson A, Anderzen-Carlsson A, Ahlin A, Andershed B. Mothers' everyday experiences of having an adult child who suffers from longterm mental illness. Issues Ment Health Nurs 2010; 31: 692-9.

29 Johansson A, Anderzen-Carlsson A, Ahlin A, Andershed B. Fathers' everyday experiences of having an adult child who suffers from longterm mental illness. Issues Ment Health Nurs 2012; 33: 109-17.

30 Sjöström B, Dahlgren LO. Applying phenomenography in nursing research. J Adv Nurs 2002; 40: 339-45.

31 The Swedish Research Council. Vetenskapsrådet. Forskningsetiska principer inom humanistisk-samhällsvetenskaplig forskning (Swe) [Principles of Research Ethics in the Humanities and Social Scientific Research], 2002, The Swedish Research Council, Stockholm.

32 Kvale S. Den kvalitativa forskningsintervjun (Swe) [The Qualitative Research Interview]. 1997, Studentlitteratur, Lund.

33 Bruce H, Evans N. The transition into adult care. Psychiatry 2008; 7 : 399-402.

34 Holm U. Modrande $\theta$ praxis. En feministfilosofisk undersökning (Swe) [Mothering $\theta$ Practice. A Feminist Philosophical Survey], 1993, Göteborg university, Göteborg, Sweden.

35 Andershed B. Att vara nära anhörig $i$ livets slut. Delaktighet $i$ ljuset - delaktighet $i$ mörkret (Swe) [Being a Close Relative in the Final Phase of Life. Involvement in the Light - Involvement in the Dark], in Department of Public Health Sciences, Section of Social Medicine, 1998, Uppsala university, Uppsala, Sweden.

36 The Swedish Council on Health Technology Assessment. Schizofreni - Läkemedelsbehandling, patientens delaktighet och vårdens organisation (swe) [Schizophrenia - Drug Therapy, Patient Involvement and Health Care Organization], 2012, The Swedish Council on Health Technology Assessment, Stockholm.

37 Schröder A, Wilde Larsson B, Ahlström G. Next of kin's conceptions of the quality of care in the psychiatric setting: a phenomenographic study. Inter J Ment Health Nurs 2007; 16: 307-17.

38 Goodwin V, Happell B. Psychiatric nurses' attitudes toward consumer and carer participation in care: part 1 exploring the issues. Policy Polit Nurs Pract 2007; 8: 276-84.

39 Sjöström S. Invocation of coercion context in compliance communication - power dynamics in psychiatric care. Int J Law Psychiatry 2006; 29: 36-47.

40 Enarsson P, Sandman PO, Hellzen O. The preservation of order: the use of common approach among staff toward clients in long-term psychiatric care. Qual Health Res 2007; 17: 718-29.

41 The National Board of Health and Welfare. Det diffusa tvånget - Patienters upplevelser av öppen tvangsvard (Swe) [The diffuse compulsion - patients 'experiences of open compulsory treatment], 2012; Available from: http://www. socialstyrelsen.se/publikationer2012/ 2012-1-35.

42 Enarsson P. Mellan frihet och trygghet: personalgemensamt förhållningssätt i psykiatrisk omvårdnad (Swe) [Between Freedom and Security - Common Staff Approach in Psychiatric Nursing], Department of Nursing, 2012, Umeå university, Umeå, Sweden.

43 World Health Organization. Zero draft: Global mental health action plan 20132020. 2012; Available from: http:// www.who.int/mental_health/mhgap/ mental_health_action_plan_EN_27_ 08_12.pdf.

44 Polit D, Beck C. Nursing Research: Principles and Methods. 2004, Lippincott Williams \& Wilkins, Philadelphia.

45 Patton M. Qualitative Research $\theta$ Evaluation Methods (3 ed.), 2002, Sage, London.

46 Bowden J. Reflections on the phenomenographic team research process. In Doing Developmental Phenomenography (Bowden J, Green P eds), 2005, RMIT University Press, Melbourne. 